\title{
Keith Ray and Julian Thomas, Neolithic Britain: The Transformation of Social Worlds
}

\author{
Oxford: Oxford University Press, 2018. Hardback, 416 pages. ISBN: \\ 978-0-19-882389-6. £30.
}

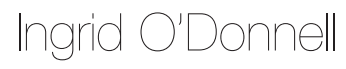

University of Wales Trinity Saint David 1503563@student.uwtsd.ac.uk

Neolithic Britain is dedicated to the memory of Andrew Sherratt and his influence in Neolithic archaeology. Consequently, this sets out to be a special book, and it does not disappoint - although its individuality makes it difficult to categorise. Whilst offering a highly detailed academic approach, as might be expected from two archaeologists with extensive experience excavating Neolithic sites, the authors emphasise that it should not be envisaged as a textbook, nor a contribution to new research. Rather, they would like it to mark a "pause for reflection" (p. 9) in the current milieu of British Neolithic study. The Foreword by Peter Florence describes the book as "the starting point of a conversation about who we are [...] a conversation with two exceptional guides" (p. viii); and this, together with the long list of well-known Neolithic researchers thanked in the Acknowledgements are early indications, not only of the wide spectrum of perspectives that will be addressed, but also that this publication is likely to offer more than a mere "pause" for reflection.

Another early indication that much thought has gone into this volume is the aesthetically eye-catching front cover, which presents an enticingly warmly lit, golden, glowing photograph of Wayland's Smithy's chambered tomb at night, inviting the reader in to experience the Neolithic, away from the cold snowy winter environment outside and also away from the dark, starless sky above, which takes up half of the front cover. It is a stunning photograph and a good representation of what the book holds in store: illustrations form a key element of the work, and include more colour photographs, by Adam Stanford, atmospheric paintings by Anna Dillon, instructive line drawings by Tim Hoverd and fabulously evocative wood engravings by Hilary Paynter. The rationale underlying the inclusion of such artistic variety is that whilst photographs can convey accuracy, other forms of illustration offer greater scope for portrayal of interpretation. 
The variety of illustrative methods supports the aim of the book, which is to offer a narrative for the changing social worlds throughout the Neolithic in Britain. The authors clarify that they do not seek to evoke the presence of Neolithic people in Britain by visualisation, and nor do they wish to evaluate the "depths of thought about unseen worlds that Aubrey Burl [1981] explored in Rites of the Gods" (p. 8). These caveats seem to imply that the book will seek to explain changing social worlds of the Neolithic with minimal reference to cosmology or ontology. Clearly, these abstract subjects are high on Hawkes' Ladder of Inference (Hawkes 1954) and are therefore difficult to examine from the material record. However, it is also hard to see how any intangible social world can be evaluated effectively without some consideration of the underpinning societal cosmology and ontology.

With this initial reservation aside, the book promises and delivers an engaging interpretative journey, examining the social dimensions of Neolithic cultural practices, whilst placing these practices within a dynamic historical framework and highlighting the possible awareness that Neolithic people may have had of their own historical antecedents. The structure adopted by the authors to achieve their purpose is twopronged: three of the five chapters falling between the Introduction and Conclusion adopt standard sequential narrative approaches to the Neolithic in Britain, and these are interspersed with two chapters that take a more thematic approach, addressing key topics which recur throughout the period. This technique of shifting focus ensures that the reader is engaged throughout, and it demonstrates multi-faceted perspectives from which it is possible to try to comprehend the British Neolithic.

The inclusion of so many of these perspectives, which have been proposed over time to further our understanding of the British Neolithic, is a chief strength of this book. The Introduction (Chapter 1) presents a detailed overview of the history of scholarly thought on the Neolithic in Britain, starting with Gordon V. Childe in the 1920s through to the post-structuralist viewpoints of Christopher Tilley in the final decade of the twentieth century. Particularly interesting in this history is the way the authors have linked the different theoretical perspectives to the societal and political influences at the time of their proposition.

The three narrative chapters examine likely social influences of the Neolithic in chronological order. "4000 BCE: A Cultural Threshold" (Chapter 2) examines the Mesolithic-Neolithic transition in clear and evocative language, while "Narratives for the Fourth Millennium" (Chapter 3 ) is a carefully nuanced account of the different historical narratives which have been proposed over time by various scholars (e.g. Stuart Piggott [1954] and David Miles [2016]). The authors are careful to acknowledge the limitations of the evidence, and they question the extent to which the data is representative for Britain or the period.

Chronologies and distributions for long barrows, timber halls, passage tombs, causewayed enclosures, cursus monuments, pottery typology and palisaded enclosures are discussed, along with an examination of what these structures and any associated mortuary and deposition finds can tell us about what was important to Neolithic society at this time. The re-use of structures such as pits, ditches, barrows, tombs and so on, 
leads the authors to emphasise the importance of veneration of already ancient sites in the Neolithic (pp. 159-165), potentially highlighting the significance of assumed descent from earlier communities. This, in combination with the development of shared resources and collective social responsibilities (p. 113), gives the first hint of the authors' proposal of "invested lineages" (p. 314) as a key social influence in the Neolithic. This proposal is expanded further in thematic Chapter 4 (discussed further below) and then narrative Chapter 5 before a full unveiling in Chapter 6.

Chapter 5, "Narratives for the Third Millennium", is concerned with the emergence of a new range of inter-regional connections across Britain and Ireland and the consequent social interactions; for example, the influence of Orkney society is correlated with the increasing distribution of Grooved Ware pottery bearing a decorative motif which possibly originated from the passage tombs of Ireland. The discussion progresses to an examination of the chronology and distribution of henge construction throughout the British Isles. This leads into a presentation on the various phases of Stonehenge and the origins of the site's bluestones and Aubrey Holes, as well as the various social theories regarding seasonal feasting, collective identity, the healing properties attributed to the bluestones and the veneration of ancestors. Lastly, the chapter addresses the arrival of the Beaker people from continental Europe and examines further the themes of continuity and transformation of social practices, particularly those related to the continuing re-use of earlier indigenous locations for burial of the dead.

One potential criticism that could be levelled throughout the book is its apparent bias for the importance of southern England in the initiation of various Neolithic developments, such as pottery and buildings (pp. 67, 73, 92, 197, 366). This culminates with the statement in the Conclusion that "the construction of Stonehenge and Avebury [...] might, quite reasonably, be identified as the apogee of the cultural possibilities that had been established during the British Neolithic" (p. 334). Aside from the astonishing dismissal of Neolithic Orkney culture here (although mentioned previously as a key contributory development), there are other smaller, continual oversights; for example, much less detail is given to Welsh monuments (for example, Dyffryn Ardudwy and Llandygai) than to the southern English counterparts like White Horse Stone (pp. 55-56, 74-75).

Admittedly, radiocarbon dates may be more available for the south of England and, to be fair, the authors do mention this bias of data availability (pp. 105-106, 119, 134, 334-335). However, they do not appear to attempt to redress this imbalance by taking account of other dating techniques. For example, a 1999 doctoral thesis by Richard Peterson (supervised by Julian Thomas) reported that sherds of the fine carinated bowl pottery from the pit in front of the oldest portal dolmen at Dyffryn Ardudwy (Meirionnydd, Wales) originated from the First Neolithic (4000-3800 BC) (Peterson 1999, 71-82, 92-96). This observation confirmed that of T. G. E. Powell (1963), who carried out the excavation at Ardudwy, noting that the pottery discovered was "of a type as early as any yet found in a megalithic tomb in the Irish Sea Zone" (p. 23). Ray and Thomas do not provide a specific reference for their later dating of the Dyffryn Ardudwy pottery at $3800-3700$ BC (p. 138) and maintain that evidence for Wales is "equivocal" (p. 138), with no further referencing or clarification to support this statement, even in their Bibliographical 
Commentary which, in this respect, offers only generally recommended reading on carinated bowls (p. 356). Their repeated assertions that the British Neolithic commenced in southern England in my view need to be argued more convincingly.

The thematic chapters, "Social Being and Cultural Practices" (Chapter 4) and "Kinship, History and Descent"(Chapter 6), provide a thought-provoking overview of different perspectives on various topics, including flint mining, pit digging (Mesolithic and Neolithic), middening, pottery, timber monuments, re-use of locations, axe heads, mortuary practice, violence and various types of depositional and site decommissioning practice. The chapters are written in an informal, easy-to-read, but also detailed, style and, in places, veer towards including welcome cosmological and ontological interpretations; for example, the authors quote Alasdair Whittle that flint axes might have been construed as "gifts from the earth" (p. 175), and that the act of creating a stone axe might have been more focused on releasing the potency of the stone material, rather than creating an actual axe head. However, such suggestions are merely touched upon. The unaddressed questions of "why?" and "what did Neolithic people believe?", and the absence of suggestions for any mythic narrative for the Neolithic in these chapters and in the wider book, are frustrating. Reverence for ancestors or past lineages might have been important, but this observation is not sufficient to provide a clear understanding of the British Neolithic and its societies. Nevertheless, the overview of the various topics is extremely engaging; it is to the authors' credit that the work leaves the reader demanding more and highlights the unanswered questions that are outside the stated remit for this book.

One noticeable omission in the book, however, is the lack of any detailed discussion of the relevance of skyscapes and consideration of archaeoastronomy. In Chapter 3, there is a brief reference to some passage tombs having an alignment on a particular celestial event, with the observation that "the interior of the tomb is illuminated by the midwinter sunset and sunrise respectively at Maes Howe in Orkney and Newgrange in Ireland" ( $p$. 164). However, the potential cosmological significance of this for Neolithic society is not explored. Mesolithic people are acknowledged as being expert mariners (pp. 52, 63), but there is no discussion of the possible astronomical basis of early people's marine navigation skills as, for example, described by Fernando Pimenta (2015). With regard to the Mesolithic pits at Warren Field, Crathes (pp. 64, 95-96, 107-110), no mention is made of their potential significance as soli-lunar calendrical markers (Gaffney et al. 2013) and, again, at the nearby henge of Broomend of Crichie (p. 261), there is no mention of the previous archaeoastronomical research conducted at this site (Henty 2015). Furthermore, no mention of potential skyscape significance is mentioned when discussing the Thornborough Henge monuments (pp. 64, 261), despite Jan Harding's detailed investigations and report on this site (Harding 2013).

Mike Parker Pearson's solstitially oriented natural periglacial fissures at Stonehenge are mentioned in Chapter 5, but there is a significant error in describing the main significant axis at Stonehenge as one relating to midsummer sunrise / midsummer sunset, rather than the correct midsummer sunrise / midwinter sunset (p. 268). This may have been merely a proofreading oversight, but the lack of concern relating to the astonishing Mesolithic and Neolithic preoccupation with monument orientation and knowledge of 
the sky is disappointing. The starless sky above Wayland's Smithy on the front cover unintentionally conveys its own meaning and the dubious reference to "more recent suggestions of priestly astronomers" in the same breath as fairies, giants and druids as an inventory of populist explanations in the Conclusion (p. 323) completes the tone of the book in this respect. This reviewer would have liked to have seen identification of key elements in Neolithic people's conception of the celestial sphere being used to explore the potential relevance these elements may have had to Neolithic cosmological, ontological and societal beliefs and practices.

Technical terminology is defined in a helpful glossary towards the end of the book, and the indexing, while adequate, is not detailed. The non-academic referencing was disappointing: to reach the end of the easy-flowing main text and then have to contend with the dense Bibliographical Commentary was a shock. Whilst it is appreciated that the authors were not aiming to produce an academic text, the flow of the book would have been improved by dividing the Commentary into separate sections and placing each at the end of the chapter to which it was relevant. The chronology chart which follows the Bibliographical Commentary is a useful ready reference.

Overall, this is an excellent, highly informative and readable text for anyone new to the subject of the Neolithic or seeking a reference on recent developments of how complicated Neolithic chronologies fit together within Britain. It is a beautifully produced, highly readable, detailed, engaging and thought-provoking, informative book, and is highly recommended.

\section{References}

Burl, A., 1981. Rites of the Gods. London: J. M. Dent.

Gaffney, V., S. Fitch, E. Ramsey, R. Yorston, E. Ch'ng, E. Baldwin, C. Bates, C. Gaffney, C. Ruggles, T. Sparrow, A. McMillan, D. Cowley, S. Fraser, C. Murray, H. Murray, E. Hopla and A. Howard, 2013. "Time and Place: A Luni-Solar 'Time-Reckoner' from the $8^{\text {th }}$ Millennium BC Scotland". Internet Archaeology 34: 1-31. https://doi.org/10.11141/ia.34.1

Harding, J., 2013. Cult, Religion and Pilgrimage: Archaeological Investigations at the Neolithic and Bronze Age Monument Complex of Thornborough, North Yorkshire. Council for British Archaeology Research Report 174. York: Council for British Archaeology.

Hawkes, C., 1954. "Archaeological Theory and Method: Some Suggestions from the Old World". American Anthropologist 56 (2): 155-168. https://doi.org/10.1525/aa.1954.56.2.02a00020

Henty, L., 2015. "A Microscopic Scale Analysis of Monuments and Ritual in Aberdeenshire". Journal of Skyscape Archaeology 1 (2): 143-173.

Miles, D., 2016. The Tale of the Axe: How the Neolithic Revolution Transformed Britain. London: Thames and Hudson.

Peterson, R. G., 1999. The Construction and Use of Categories of Neolithic Pottery from Wales. PhD diss, University of Southampton, Southampton.

Piggott, S., 1954. The Neolithic Cultures of the British Isles: A Study of the Stone-Using Agricultural Communities of Britain in the Second Millennium B.C. Cambridge: Cambridge University Press.

Pimenta, F., 2015. "Astronomy and Navigation". In Handbook of Archaeoastronomy and Ethnoastronomy, edited by C. L. N. Ruggles, 43-65. New York: Springer. https://doi.org/10.1007/978-1-4614-6141-8_7

Powell, T. G. E., 1963. "The Chambered Cairn at Dyffryn Ardudwy". Antiquity 37 (145): 19-24. https://doi.org /10.1017/S0003598X0003698X 